\title{
Marshall syndrome
}

INSERM

\section{Source}

INSERM. (1999). Orphanet: an online rare disease and orphan drug data base. Marshall syndrome. ORPHA:560

Marshall syndrome is a malformation syndrome that is characterized by facial dysmorphism, severe hypoplasia of the nasal bones and frontal sinuses, ocular involvement, early-onset hearing loss, skeletal and anhidrotic ectodermal anomalies and short stature with spondyloepiphyseal dysplasia and early-onset osteoarthritis. 